\title{
Colloquium
}

\section{Becoming Rhizome Researchers}

Bryan Clarke bclarke1@ualberta.ca

University of Alberta, Canada.

Jim Parsons jim.parsons@ualberta.ca

University of Alberta, Canada.

\section{Abstract}

Binaries affect many aspects of educational discourse including research and teaching. Although not every binary is negative towards educational 'forward' movement, the authors propose that rhizomatic thinking, derived from the writing of Deleuze and Guattari, can open new potentialities for a breaking of different types of binary thinking. Adopting the terminology of rhizomatic research they outline ways that re-envision educational research through the concept of the rhizome, as a hopeful pathway towards new ways of teaching and research. As a guiding quasi-methodology, rhizomatics could help researchers/teachers develop agency but step beyond personal agency to see research/teaching through multiplicities that arise rather than pre-planned forged curricula. Starting in the middle, the authors suggest that rhizome researchers recognize their embeddedness, allow research to lead them, accept that attempts to synthesize are never finished, listen to those before them and on the margins, and give themselves to a life of becoming, thus 'breaking' the binaries that can capture or stifle their attempts to be educational researchers constructing symbolic selves.

Key Words: rhizome, binary, education, Deleuze, research, curriculum.

Developing the necessary skills, aptitudes, and philosophy to be a research-oriented educator is a journey of agency. One concomitant learning in the growth from novice to experienced researcher is the growing belief that one can make a difference in the world - that engaging in research can help change some part of the world for the better. It seems almost impossible, unless one approaches research as a hack, that one can enter the work of research without an accompanying belief that the energy and actions poured into research promise that the work will successfully bring improvement. Research is academic work fuelled by a promise of change as the 'affect' of research go beyond what can be simply represented. 
Our experience researching, teaching research design, and working with graduate students who conduct their own research is that research engages them in a process of personal growth. This growth goes beyond what we could chart or delineate ahead of time, as affect in Deleuzian sense can emerge in so many ways, from experiences that could be deemed positive steps forward to the deconstructing that occurs to naïve conceptions as students face daily reality that don't fit into neat knowledge packages. Ironically, our experience suggests that most graduate students enter their research a bit in awe of academic researchers and a bit overwhelmed at the thought of conducting their own research. However, having engaged in research, they often emerge with a passion for research and a continuing respect for researchers; however, the research awe has been replaced with collegial respect and awareness of vast fields of complexity. Many new researchers, if not most, come to see research in revised ways - but not research as they first envisioned. Simplified binaries of qualitative vs. quantitative no longer hold sway as they develop awareness for what Kristeva calls the 'abject', or what one might call being caught in paradox, or Heidegger called unheimlichkeit or 'strangeness'. We have seen this affect cannot be specifically planned for but can be expected of our developing graduate researchers, even challenging the timeline for completing research as ideas change in flux.

\section{Research As Agency}

In 1976, Walker Percy wrote the odd titled book The Message in the Bottle. In this book, Percy conceptualizes "The Delta Factor" using the story of Helen Keller's breakthrough in learning as Annie Sullivan (1) poured water over her hands and (2) repeatedly signed the word for water into her hand. Percy theorizes that this action was more than simple cause and effect (or intermittent conditioning) because Keller received more than the signifier (the sign for water) and the referent (the water itself). Percy believed the breakthrough came as Annie Sullivan created a triadic relationship between water (the word), water (the liquid), and Helen herself - who was acting with agency to bridge word and substance. These "three corners" - the Delta $\Delta$ - were, as Percy saw it, the "absolutely irreducible" building blocks of human intelligence. In Percy's construction, Keller became more than organism responding to her environment. Suddenly, she was able to connect two unrelated things - (1) water the word and (2) water the liquid - and gained agency and insight by doing so.

Our point is that "water the liquid" becomes more than liquid because it connects the substance (water), with the word (for water), with the identity of the human engaged in the naming (Helen, herself). In terms of doing research, to state it directly, researchers do more than collect data and analyze findings. Research also becomes a symbolic construction of self as the researcher gains agency and comes to selfidentify and act as a researcher. Thus, the activity of conducting research shapes the lives and identities of those forging the constructions (doing the research). In other words, research is always more than research, because it is conducted and constructed by people who (by doing research) engage in the complex challenge of symbolic meaning-making and identity-building, informed by changing life narratives. While recognizing the term 'learn' is loaded with multiplicities of signification, researchers 'learn' about themselves as they conduct research, becoming researchers who act as their community of researchers act. Research changes the researcher in often inexplicable ways. When we use term 'learning' we are assuming a multi-faceted, ongoing development within a person. Here we define learning broadly, in non-measurable ways that lack linearity and easy categorization. As we see and have experienced it, becoming-researchers defy checklists, standardization, system, and clear cut identities. 
Thus, the methods of doing research ("water the word") and the data or findings of research ("water the liquid") shape researchers' identities (as they do research). Research itself is much more than creating a methodological proposal for collecting data. It is a building block of human knowing, a complexified form of learning and human identity forming where the whole of the research is greater than the sum of the parts. Specifically, as researchers came to conduct their own research at their own sites, they came to identify as researchers - adding to their identities as leaders-acting with agency in space (see Sheerin's 2009 discussion of the complexities related to identity through his study of Ricoeur and Deleuze).

Although we will not discuss it in depth, this view of research is sometimes uncommon in academic contexts. We have seen power contestations within normative contexts housed in traditional research ethics forms that must be filled out prior to conducting research with human subjects. At many universities, the research ethics process is clearly grounded upon a traditional scientistic ideology where knowledgeable researchers hold a hierarchical - almost patronizing - relationship with research subjects whom they promise not to harm. In contrast, our experience is that most research is conducted by trusting peers working collaboratively within a community, most of whom would never consider advantage over colleagues as a status to be claimed because they all - together - have a vested interest in improving their learning and communities. These experiences do not delimit the insidious (and very human) potential for ambition and jealousy to impact research projects; it does, however, suggest that, in sites where research is engaged within a trusting professional community, empowerment often becomes a force for change.

\section{Becoming a Rhizome Researcher}

In this article, we will outline a process of what we call rhizome research and suggest ways researchers can become rhizome researchers. This learning process is one both authors have experienced in different ways that has shaped our approaches to research and to academic life. We have engaged in debates about qualitative and quantitative research, and will continue to do so. However, we desire to go beyond this constructed binary to become part of a reframing and reconceptualising of what we see as categories too firmly entrenched in ideologies of representation and objectification rather than open to allowing research to go where it leads and take us where it goes. The path is, for us, a path of agency. Thus, the idea was born for us to think of research as rhizomatic or becoming rhizome researchers. This different way of framing our research has helped open up new perspectives on our educational journey.

\section{Deleuze and Guattari}

We see research opening us towards seeing interconnections rather than separations. Deleuze and Guattari (1987) explicated this conceptualization in their concept of a rhizome. Because we are teachers, we will conform our thinking about research with our thinking about teaching. We believe identity as a teacher is not separate from living as a researcher. Rather, our better teachers always critically searched for meaning. These teachers interpreted each day as it came and lived and shared their research from where they were living intermezzo (a short piece of instrumental music used between acts or scenes of an opera or drama). For example, each day one enters the classroom, besides the pulling together of tests, articles, art, and other media, a teacher's routine consists of ongoing 
research: searching out etymologies, popular culture, current statistics, global political events, books, and many other typically mundane yet research oriented resources. Especially movies and television series seem amply suitable in contributing to grappling with a world of change, creativity, and potentialities. We see, with TED talks ${ }^{1}$ and the ubiquitous YouTube, teachers are now even less the 'informers' or 'tellers' and more the co-researchers.

Every day events from media draw us into a global discussion through Twitter, Facebook and the like, each informing us through blogs, movie, books, and television filled with rants, academic discourse, and diversified discussions. How is one to develop oneself as researcher let alone a classroom full of students from multiple backgrounds? Declan (2009) points back to the 1982 movie classic Blade Runner as a "quest for immortality and the meaning of human being and having selfhood", which problematizes personal identity through the memory in relationship to the narrative self (p. 15). The androids in film are searching for their creator wanting to prolong their lives raising questions such as: Are the android's becoming human or vice-versa; what is the category of 'human being'? Deleuze's idea of the virtual and Ricoeur's Oneself as Another are two responses to the ongoing challenge of agencies and identities raised by media, worth applying to becoming-researcher. A discussion that points to the practical yet complex day-to-day interconnections with students, teachers, research, and information that go beyond the linearity of books; students and teachers as researchers grow through personal agency and multiperspectival identities in a rhizomic fashion.

Deleuze and Guattari (1987) wrote about two types of books - the root book and rhizome book. The root book depends on foundations, linear logic, imitation, plotted points, fixed order, and a reflected image of the world - dualism in its many forms. Although root books have become standard, they have missed organic connections to the way of the rhizome:

One becomes two: whenever we encounter this formula, even stated strategically by Mao or understood in the most 'dialectical' way possible, what we have before us is the most classical and well reflected, oldest, and weariest kind of thought. Nature doesn't work that way: in nature, roots are taproots with a more multiple, lateral, and circular system of ramification, rather than a dichotomous one. Thought lags behind nature (Deleuze \& Guattari, 1987, p. 5).

Although many are committed to root books because there is an abundance of "trees" in the world, Deleuze and Guattari point to a way to get beyond what they call a weary way of thinking where thought lags behind the times to an untapped aspect of the natural order. Root book, binary thinking permeates Western society, so deeply embedded that this thinking is accepted without question; yet, this thinking misses the point by limiting and decomplexifying in ways that disallow openness to what could be. As Deleuze and Guattari (1987) say, "Binary logic is the spiritual reality of the root-tree" (p. 5). If that is the case - that this 'spiritual' reality dominates and limits - continuing root thinking truncates creative growth. Deleuze and Guattari (1987) posit instead the rhizome book - which morphs, redirects, and moves in multiple directions at once.

\footnotetext{
${ }^{1}$ http://www.ted.com/promos/TEDTalksEducation
} 
A rhizome ceaselessly establishes connections between semiotic chains, organizations of power, and circumstances relative to the arts, sciences, and social struggles. A semiotic chain is like a tuber agglomerating diverse acts, not only linguistic, but also perceptive, mimetic, gestural, and cognitive: there is no language in itself, nor are there any linguistic universals, only a throng of dialects, patois, slangs, and specialized languages (p. 7).

Seeing the world as rhizome book rather than root book, rhizomatically instead of arboretically, shifts one away from binary oppositions. Rather than subject/object or transcendence/immanence, the way of the rhizome opens one to a way of becoming, a univocity (one voice) that could unleash forces that are bound, captured, and limited to working with either/or logics. As powerful and as helpful as binaries are for seeing options and simplifying choices, we propose stepping forward as educational researchers toward seeing rhizomatic research as a shift in direction derived from Deleuzian and Guattarian concepts.

Thus, as we have come to think of research as rhizomatic, we have come to reframe research as rhizome researchers - an act that has helped us open new perspectives on our educational journey. Below, we explicate these new perspectives that emerge from thinking as a rhizome researcher/teacher:

\section{1) Rhizome researchers start where they are (nomadic)}

When deciding to research as a rhizome, researchers begin to see their current situatedness as an opportunity to be (Deleuze and Guattari) nomadic - to live outside the current state of affairs. The nomad intentionally lives without roots; willingly moves from place to place, idea to idea, and concept to concept. Nomads are open to interrelationships of what is before them, even if these interrelationships present places and concepts not traditionally linked. According to Deleuze and Guattari, being a nomad means that:

The nomad has a territory; he (sic) follows customary paths; he goes from one point to another; he is not ignorant of points (water points, dwelling points, assembly points, etc.). But the question is what in nomad life is a principle and what is only a consequence. To begin with, although the points determine paths, they are strictly subordinated to the paths they determine, the reverse happens with the sedentary. The water point is reached only in order to be left behind; every point is a relay and exists only as a relay. A path is always between two points, but the in-between has taken on all the consistency and enjoys both an autonomy and a direction of its own. The life of the nomad is the intermezzo. (Deleuze \& Guattari, 1987, p. 380).

Nomadic research is open to and satisfied with being in current space and time; there is no reason to live in another geography or in the past or future. One does not forget what is backwards or forwards; rather, one deliberately chooses to be and to live in the now without resorting to elements beyond close reach and proximity.

2) Rhizome researchers listen to the voices/things connected to them (assemblages)

Deleuze and Guattari's concept of the assemblage provides researchers ways to view students and research by shifting away from binary oppositions and hierarchies such as male/female, ethnic/non- 
ethnic (itself a misnomer), and teacher/student. This provision means deliberately seeing things and people around you with intentional equality, respect, and presence. Elements that seem less likely to provide opportunities for research insight aren't immediately dismissed but remain in the purview because the researcher sees assemblages in relationship and views synthesis rather than analysis.

3) Rhizome researchers embed themselves in the lives of their research/students (plane of immanence)

We believe Deleuze and Guattari's concept plane of immanence is more than an ontologically powerful way of conceiving things: it is also a way of living as researchers who become embedded and committed to research and people. Although negative bias should be fought in our own subjectivities, we believe forming a bias for those we are working with that connects and gives us access to authentic lives is inherently positive. Recognizing that, with Ricoeur, understanding is always provisional (Ihde, p. 12), we see closer formations of researcher and students allowing entrance and permission to hear perspectives less open to the public. Not looking outside ourselves or those involved in our research to compare against and living in view of the plane of immanence gives research a freedom to follow lines of flight and seeks to break free from objectifying people as we consider ourselves as rhizomatically embedded to the 'other.' Thus, we see difference as positive and not as a lack.

4) Rhizome researchers develop sensitivities to elements/people that are not part of the status quo (deterritorialization)

Attempting to totalize and build hierarchies are ongoing temptations for researchers in an educational environment that often feels out of control or has already become territorialized by stifling oversimplifications. Rhizomatic thinking steps into the affect, creating moments of what Deleuze and Guattari call deterritorialization that embrace chaos and creativity as things to be celebrated and encouraged rather than shut down, captured, pushed out, dis-affected, or diminished (made small, lessened). Researchers should be aware of those on the fringe and come to see 'all' those being researched and 'all' the information being gathered, including disparate elements that seem out of line with preconceived notions. Rhizome researchers can problematize the status quo to ask hard questions about what is happening that deflate educational hegemonies. Even situations that seem lethargic may have reasons that unfold beyond our intuitions. For example, if one entered and assessed a situation without understanding cultural context, it might appear that a Chinese educational environment was lifeless, sombre, or deeply silent. Ironically, however, Chinese students often become more still as they listen intently and engage more fully. Thus, a rhizomatic researcher's skill set requires a highly adaptive way of viewing research/teaching situations.

5) Rhizome researchers search for research aspects that are sometimes ignored (different affects)

Deleuzian scholar, Brian Massumi (1987) defines affect and affection in the Preface of $A$ Thousand Plateaus:

Neither word denotes a personal feeling (sentiment in Deleuze and Guattari). L'affect (Spinoza's affectus) is an ability to affect and be affected. It is a prepersonal intensity corresponding to the passage from one experiential state of the body to another and implying an augmentation or diminution in that body's capacity to act. L'affection (Spinoza's affectio) is each such state considered as an encounter between the affected 
body and a second, affecting, body (with body taken in its broadest possible sense to include "mental" or ideal bodies) (p. xvi).

Researchers who follow traditional research paradigms can fall prey to searching for preconcieved results, what Deleuze calls the danger of representation. Researching as a rhizome highlights the possibility of seeking the preconceived and searches for ways to allow pre-personal intensities - the affect - to be in purview of research and pedagogy. Such affect is generated not from the researcher's agenda, but from the researcher entering the strange release from seeking to control research projects or students. Allowing a research project to control itself is easier said than done, but we believe such openness to affect can negate preconceived conceptions of research that stagnate towards the norm.

Allowance for this affect can work in research and critique representation when beginning a research project. Justifiably, a temptation for researchers is to have an intuitive sense of their research trajectory but, keeping the rhizomic perspective in view, one can work at being less directed by these early assumptions of trajectory and open to that which affects ideas and perspective in toto. Practically, this could mean that, when someone is writing an essay-based dissertation, the subjects chosen for research are less prescribed and outlined chronologically on a timeline from the beginning and allowed to morph from coursework, reading, collegial interactions, and classroom placements. Receiving this affect would include the intentional openness to opinions outside of one's own scope and purview and move a researcher in rhizomic directions rather than linear fashion, finding unlikely connections. Granted, this way of working might deter efficiency and challenge standardized bureaucracies and doctoral graduation timelines, yet the allowance for creativity and openness would positively complexify research pathways that follow the more traditional and representational and can get caught in stale repetition trying to resemble that which was before rather than re-envision something new.

6) Rhizome researchers desire a life of becoming rather than copying what is seen (haeccity and multiplicity)

Multiplicities are rhizomatic and expose arborescent pseudo-multiplicities because there is no unity to serve as a pivot in the object or to divide in the subject. There is not even the unity to abort in the object "return" in the subject because a multiplicity has neither subject nor object, only determinations, magnitudes, and dimensions that cannot increase without the multiplicity changing its nature. The laws of combination therefore increase in number as the multiplicity grows (Deleuze, 1987, p. 8).

In Dialogues, Deleuze (2002) states: "In a multiplicity what counts are not... the elements, but what there is between, the between, a site of relations which are not separable from each other. Every multiplicity grows in the middle" ( $p$. viii). Thinking this way can be challenging; however, that challenge is part of the energy rhizomes can exert for thinking differently and thinking 'difference' rather than 'sameness.' Rhizomatic thinking challenges the binary mindset that depends upon finding foundations and relies on a representational horizon - comparison to what 'is' rather than openness to the future. For Deleuze (2006), clear-cut binaries are but "molar or massive effects occurring within 'multiplicities." (p.70). From this insight, we can see that there is a 'breaking' with binaries that opens up possibilities of re-envisioning research. 


\section{Breaking Binaries}

In critical theory, binary oppositions are pairs of related terms or concepts opposite in meaning. Binary opposition is a system in language and thought where two theoretical opposites are strictly defined and set off against one another - such as contrasts between mutually exclusive terms (on and off, in and out, or quantitative and qualitative). From our current binary research, we see the potentialities of how breaking a binary can be used to (1) shift one's current research approach, (2) expand/reform pedagogical methodology, and (3) revitalize educational practice.

First, shifting one's current research approach as a way to break binaries can open new avenues of exploration, re-establishing new concept tools for understanding and carrying out research. Second, using research to expand and reform pedagogical methodology opens researchers to creatively linking pedagogy with research - a rhizomatic conversation between researching and teaching colleagues that can help shape research findings into pedagogical or curriculum ideas. The fear of missing something can be replaced with an exploratory sense that each day contains new opportunities. Teachers, who may become set in particular teaching patterns and entrenched curriculum paths, might become less content with "what they have always done." When research becomes a rhizomatic path toward breaking binaries (between researching and teaching), the conversational act of resurrecting pedagogical ideas becomes a powerful educational possibility.

Third, building from rhizomatic conversations between research and pedagogy promises to revitalize educational practice. How might educational practices, for example, reflect rhizomatic research? In a rhizomatic world, there may be little distinction between a rhizomatic researcher and a rhizomatic teacher. Each day explores opportunities to try new ideas, to work in the middle synthesizing student interests and curriculum goals. Rhizomatic teachers/researchers can take steps towards giving some control, allowing students' and teachers' ideas to merge in ways that incorporate core aspects of required curriculum. Researchers and teachers can 'break' towards a lived curriculum "for a people yet to come" (Wallin, 2011) and seek ways to become that allow more flow, even within the constraints of binding bureaucracies.

\section{Conclusion}

Rhizome researchers have many conceptual tools at their disposal that can open lines of flight, enhance or uncover affect, release the need for control, situate one's self in embeddedness as a normal research situation, accept assemblages that constitute groupings of multiple groupings, and live within Deleuze's and Guattari's concept of becoming as day-to-day experiential learning. The beauty of these tools is that they are non-manipulative and seek to enhance educational flourishing by working against systems that can resort, if allowed, to power brokerage. Ideally, lines of flight can move students towards positive new outcomes in ways that might change a stagnant classroom to a place of expectation. Pressure to be everything to everyone is released, and possibilities for wider assemblages of contributors can encourage openness to new potentials. Perhaps the joy of research can be ignited when the responsibility to make things happen is let go.

\section{References}

Deal, W. E., \& Beal, T. K. (2004). Theory for religious studies. New York, NY: 
Routledge.

Deleuze, G. \& Parnet, C. (2002). Dialogues. Trans H. Tomlinson. Continuum.

Deleuze, G., \& Guattari, F. (1987). A thousand plateaus: Capitalism and schizophrenia.

Trans. and foreword by Brian Massumi. Minneapolis and London: University of Minnessota

Press.

Deleuze, G. (2006). Foucault. New York, NY: Continuum.

Ihde, D. (1971). Hermeneutic phenomenology: The philosophy of Paul Ricoeur.

Evanston: Northwestern University Press.

Patton, P. (2010). Deleuzian concepts: Philosophy, colonization, politics. Stanford: Stanford University Press.

Percy, W. (1976). The message in the bottle, Farrar, Straus \& Giroux, New York.

Ricoeur, P. (1992). Oneself as another. (K. Blamey, Trans.). Chicago and London: Chicago University Press.

Sheerin, D. (2009). Deleuze and Ricoeur: Disavowed affinities and the narrative self. NewYork, NY: Continuum.

Smith, D. \& Protevi, J. (2012). Gilles Deleuze. The Stanford Encyclopedia of

Philosophy, Edward N. Zalta (ed.), URL <http://plato.stanford.edu/archives/win2012/entries/deleuze/>.

Wallin, J. (2011). What is curriculum theorizing: For a people yet to come. Stud Philos

Educ. 30:285-301.DOI 10.1007/s11217-010-9210-y 